\title{
Internal Capsule and Splenial Lesions in Hypoglycemic Hemiparesis
}

\author{
Yoshiharu Taguchi ${ }^{1,2}$, Hironaga Kamiyama ${ }^{2}$, Michiya Kubo ${ }^{2}$ and Yukio Horie ${ }^{2}$
}

Key words: hypoglycemia, splenium, hypoglycemic hemiparesis, diffusion-weighted imaging

(Intern Med 50: 533-534, 2011)

(DOI: 10.2169/internalmedicine.50.4756)

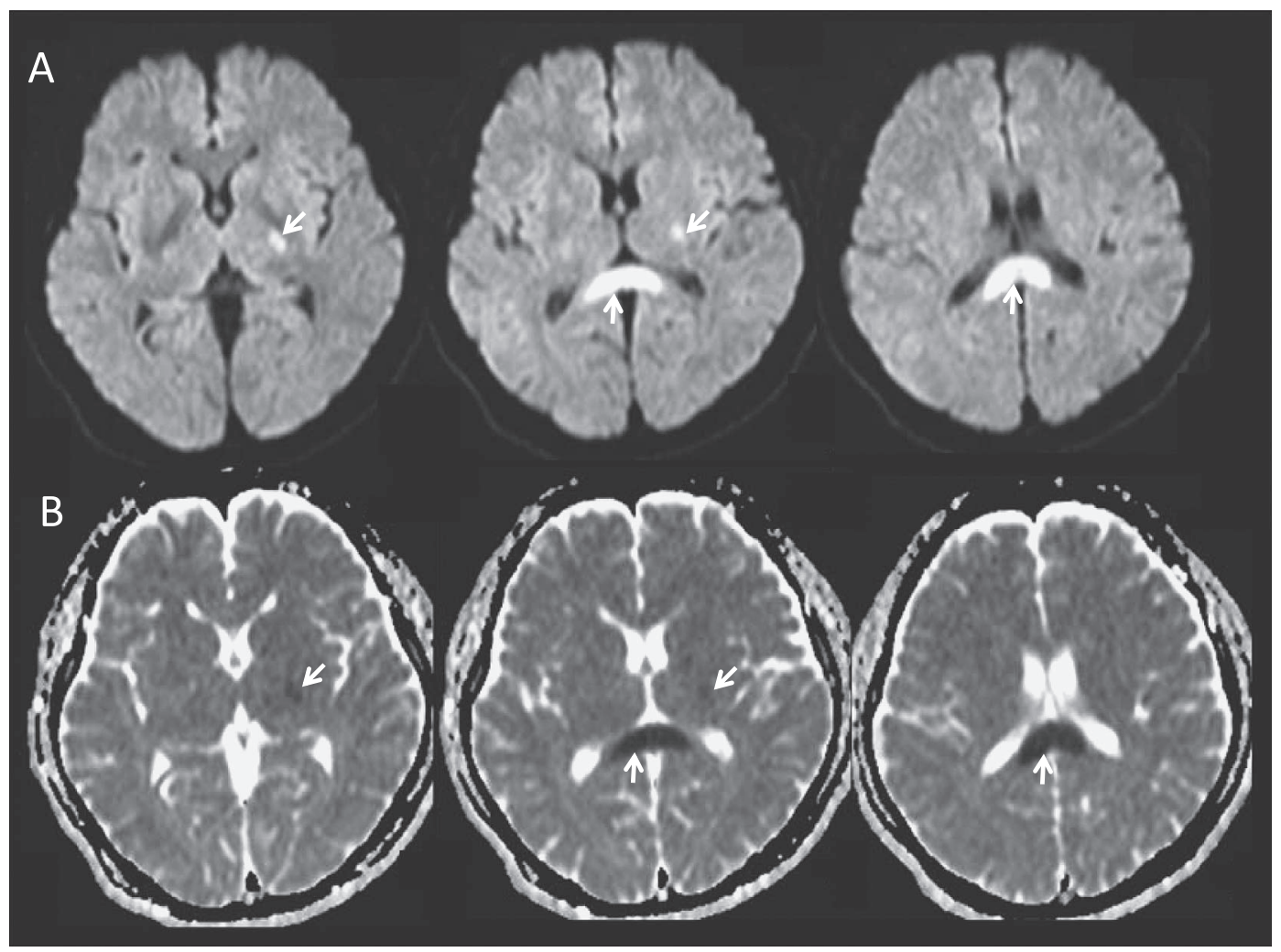

Picture 1.

A 41-year-old man with a 7-year history of insulindependent type I diabetes mellitus complained of right hemiparesis and was referred to our stroke center. Neurological examination revealed that his consciousness was alert, and he had dysarthria and right hemiparesis. Laboratory test values were within normal limits except for plasma glucose level (46 mg/dL). The dysarthria and right hemiparesis disappeared rapidly after glucose infusion. Diffusionweighted imaging (DWI) (Picture 1A) performed 1 hour after admission revealed high-signal lesions with a reduced apparent diffusion coefficient (Picture 1B) in the left internal capsule and the splenium of the corpus callosum. T2weighted image showed no abnormalities. There was no stenosis of the major cerebral arteries on magnetic resonance angiography. The patient was diagnosed as having hypoglycemic hemiparesis with lesions in the internal capsule and splenium, as revealed by DWI. Hypoglycemia should be considered as a cause of hemiparesis and a cause of splenial lesions on DWI $(1,2)$.

${ }^{1}$ Department of Neurology, Toyama University Hospital, Japan and ${ }^{2}$ Department of Neurosurgery, Saiseikai Toyama Hospital, Japan Received for publication November 1, 2010; Accepted for publication November 16, 2010 Correspondence to Dr. Yoshiharu Taguchi, ytagu@med.u-toyama.ac.jp 
Intern Med 50: 533-534, 2011 DOI: 10.2169/internalmedicine.50.4756

The authors state that they have no Conflict of Interest (COI).

\section{References}

1. Terakawa Y, Tsuyuguchi N, Nunomura K, et al. Reversible diffusion-weighted imaging changes in the splenium of the corpus callosum and internal capsule associated with hypoglycemia. Case report. Neurol Med Chir (Tokyo) 47: 486-488, 2007.

2. Yamashita S, Kawakita K, Hosomi N, et al. Reversible magnetic resonance imaging changes associated with hypoglicemia. Case report. Neurol Med Chir (Tokyo) 50: 651-654, 2010.

(C) 2011 The Japanese Society of Internal Medicine http://www.naika.or.jp/imindex.html 